\section{Demise of the} monograph

Sir - It seems that everyone laments the publish-or-perish syndrome afflicting the modern scientific community ${ }^{1}$. An unfortunate consequence of the increasing emphasis placed by funding bodies on numbers of research papers rather than overall quality of research has been the demise of the monograph.

Rather than writing comprehensive, integrated works, scientists today are encouraged to split their output into minimum publishable units. These 'paperlets' are either difficult to understand by themselves or result in much repetition due to necessary references to related paperlets. So shorter papers do not save journal space, but instead contribute to the publication explosion plaguing editors ${ }^{1}$.

They also make things difficult for scientists, as the information is not available in a single comprehensive work but is scattered in several places.

Another equally important but less discussed factor leading to the demise of comprehensive research papers has been pressure from publishers and editors. More and more journals are imposing strict page limits: there are now almost no high-profile journals with a general readership that publish monographs. In contrast, the number of leading journals that publish only short papers has increased. It is no longer worthwhile writing longer papers because of the lack of high-profile journals that will publish them.

Philosophical Transactions $A$ and $B$, the world's oldest journals, have bravely defied this trend. In my area (systematic biology), Phil. Trans. B is now the only high-profile general outlet for lengthy primary research reports. Such papers must otherwise be diverted to specialist journals, such as the Linnean Society publications, or museum annals with limited readership.

The last bastion of the monograph is, however, about to fall: it has just been announced that from 1 July, Phil. Trans. A and $B$ will no longer accept primary research papers. Instead, they will publish only reviews and theme volumes ${ }^{2}$. Although the reasons were not specified, it is likely that the financial and logistical strain of processing and publishing monographs forced the shift. No doubt Phil. Trans. will continue to publish important and timely review papers and anthologies. But this proposed niche is already occupied by several journals, such as Biological Reviews, Quarterly Review of Biology and Annual Review of Ecology and Systematics. From July, the unique role Phil. Trans. A and $B$ now perform for the scientific community (as two of the few remaining high-profile periodicals publishing detailed empirical papers of lasting importance) will end. And with fewer influential outlets for the comprehensive research paper — which everyone agrees is preferable to a plethora of insubstantial paperlets - scientists will be discouraged more than ever from writing them.

Michael S. Y. Lee

School of Biological Sciences,

University of Sydney, Sydney,

NSW 2006, Australia

e-mail:msylee@bio.usyd.edu.au

1. Werner, Y. L. in Scientific Information Transfer: The Editor's Role (ed. Balaban, M.) 113-121 (Reidel, Dordrecht, 1978).

2. Wall, P. D. Phil. Trans. R. Soc. B 352, 255 (1997).

\section{Events at Jena institute}

Sir - The News article about the Institute for Molecular Biotechnology (IMB) in Jena (Nature 385, 761; 1997) reported on the detailed internal affairs of the institute in an incomplete and one-sided way. I should like to respond to some of the statements in the article which I consider to be misleading.

Peter Schuster returned to Vienna because his three-year leave of absence from his home university ended in February 1995, but the article refers only to Schuster's 
complaints about bureaucracy at the IMB.

He turned down a permanent professorship at the University of Jena, and the opportunity to continue as scientific director of the IMB after negotiations with his home university in Vienna.

On the other hand, because of the excellent research facilities at the IMB, Schuster did not want to step down from his position as head of the IMB's evolutionary biology group. Because the IMB valued his expertise as an evolutionary biologist, Schuster was given the opportunity to run the IMB group from Vienna, but the geographical distance proved too much and left a noticeable leadership gap in the group.

The article refers to our cooperation with industry as "source of conflict", but cooperation with industry is a declared goal of the IMB, which has a considerable number of project contracts with industrial partners.

I should also like to point out that IMB scientists have themselves contributed to the situation at our institute. Early in 1996, some scientists chose not to use one of the several routine channels of in-house discussion, but instead complained anonymously to the press. Group leaders complained about the decision of the scientific advisory board, headed by Professor Rudolf Rigler, to keep evaluation reports confidential, although this is normal procedure.

The contracts of two of Schuster's senior scientists ended in the autumn of 1996 and were supposed to be extended, assuming positive results from a pending evaluation of Schuster's group. Only after the scientists had appealed to the IMB's Kuratorium (supervisory board) and had made public complaints, including serious accusations against both directors of the IMB, did the scientific director decide not to renew their contracts.

As a result, the reputation of the IMB has been severely damaged, first by scientists of the IMB, including Schuster, who made their problems public before attempting to solve them in-house, second by lack of agreement of the chairman of the scientific council with members of the Kuratorium and the institute's directors, and last but not least by the publication of magazine articles.

Now that Schuster and Rigler have resigned, the IMB scientists can return to their proper task and, by using the outstanding technical facilities and funding at the IMB, can convince the scientific community of their quality by their achievements in research and development. Stephan Diekmann Institute for Molecular Biotechnology, Beutenbergstr. 11, D-07745 Jena, Germany
Biology, not microbiology

Sir - Contrary to what Kent, Scott-Ram and Thomas say (Nature 386, 641; 1997), European patent law does not exclude "biological materials derived from 'essentially microbiological processes'”.

The European patent law, in its unfortunate language in Article 53 (b) EPC, expressly confirms the patentability of "microbiological processes or the products thereof".

Volker Vossius

Holbeinstr. 5,

D-81679 München,

Germany

e-mail:dr.volker.vossius@t-online.de

Scott-Ram replies - The sentence should have referred to "biological processes". The point that we were trying to make, and which still stands, is that one cannot "make use of a microbiological process in obtaining plants or animals only in order to be able to patent them".

\section{Nick Scott-Ram}

British Biotech Pharmaceuticals Ltd,

Watlington Road,

Oxford OX4 5LY, UK 